\title{
Seasonal Effects on Human Striatal Presynaptic Dopamine Synthesis
}

\author{
Daniel P. Eisenberg, Philip D. Kohn, Erica B. Baller, Joel A. Bronstein, Joseph C. Masdeu, and Karen F. Berman \\ Section on Integrative Neuroimaging, Clinical Brain Disorders Branch, Genes Cognition and Psychosis Program, National Institute of Mental Health, \\ National Institutes of Health, Department of Health and Human Services, Bethesda, Maryland 20892
}

\begin{abstract}
Past studies in rodents have demonstrated circannual variation in central dopaminergic activity as well as a host of compelling interactions between melatonin — a scotoperiod-responsive neurohormone closely tied to seasonal adaptation—and dopamine in the striatum and in midbrain neuronal populations with striatal projections. In humans, seasonal effects have been described for dopaminergic markers in CSF and postmortem brain, and there exists a range of affective, psychotic, and substance abuse disorders that have been associated with both seasonal symptomatic fluctuations and dopamine neurotransmission abnormalities. Together, these data indirectly suggest a potentially crucial link between circannual biorhythms and central dopamine systems. However, seasonal effects on dopamine function in the living, healthy human brain have never been tested. For this study, 86 healthy adults underwent ${ }^{18} \mathrm{~F}$-DOPA positron emission tomography scanning, each at a different time throughout the year. Striatal regions of interest (ROIs) were evaluated for differences in presynaptic dopamine synthesis, measured by the kinetic rate constant, $K_{\mathrm{i}}$, between fall-winter and spring-summer scans. Analyses comparing ROI average $K_{\mathrm{i}}$ values showed significantly greater putamen ${ }^{18} \mathrm{~F}$-DOPA $K_{\mathrm{i}}$ in the fall-winter relative to the spring-summer group $(p=0.038)$. Analyses comparing voxelwise $K_{\mathrm{i}}$ values confirmed this finding and evidenced intrastriatal localization of seasonal effects to the caudal putamen ( $p<0.05$, false-discovery rate corrected), a region that receives dopaminergic input predominantly from the substantia nigra. These data are the first to directly demonstrate a seasonal effect on striatal presynaptic dopamine synthesis and merit future research aimed at elucidating underlying mechanisms and implications for neuropsychiatric disease and new treatment approaches.
\end{abstract}

\section{Introduction}

Several lines of evidence suggest an important relationship between circannual changes in circadian rhythms and central dopaminergic systems. In rodents, striatal dopamine receptor binding shows a season- and photoperiod-specific pattern (Naber et al., 1981). Melatonin, a scotoperiod-responsive pineal hormone central to seasonal and circadian cycles (Wehr, 1997) with receptors abundant in the dopaminergic midbrain and in the striatum (Uz et al., 2005), exerts direct inhibitory effects on caudate-putamen neural activity (Castillo-Romero et al., 1993), impacting circadian changes in striatal clock gene expression and specifically inhibiting nocturnal cocaine sensitization behavior (Uz et al., 2003). Additionally, melatonin selectively induces tyrosine hydroxylase protein and tyrosine hydroxylase mRNA expression in rodent ventral mesencephalon (Venero et al., 2002), suggesting that melatonin upregulates dopamine synthesis in neuronal populations that project to the striatum.

To what degree these animal findings are relevant to human brain physiology has not been well studied, despite implications of

Received April 16, 2010; revised Sept. 17, 2010; accepted Sept. 20, 2010.

This research was supported by the Intramural Research Program, National Institute of Mental Health, National Institutes of Health. We thank the staff of the NIH PET Center for their assistance in data acquisition.

The authors declare no financial conflict of interest with regard to this manuscript.

Correspondence should be addressed to Dr. Karen F. Berman, Section on Integrative Neuroimaging, National Institute of Mental Health, NIH, 9000 Rockville Pike, Building 10, Room 3C209, Bethesda, MD 20892-1365. E-mail: Karen.Berman@nih.gov.

DOI:10.1523/JNEUROSCI.1953-10.2010

Copyright $\odot 2010$ the authors $\quad 0270-6474 / 10 / 3014691-04 \$ 15.00 / 0$ circannual biorhythms in the pathophysiology and clinical phenotypes of several major neuropsychiatric illnesses that involve the dopamine system, including seasonal affective disorder (Rosenthal et al., 1984; Neumeister et al., 2001), bipolar illness (Lewy et al., 1982; Rosenthal et al., 1983; Wong et al., 1997; Zarate et al., 2004; Roybal et al., 2007), major depression (Sher et al., 2005; Cannon et al., 2009), schizophrenia (Karson et al., 1984; Reith et al., 1994), and stimulant abuse (Huerta-Fontela et al., 2008; Mari et al., 2009). Studies in humans have reported higher fall and winter than spring and summer dopamine or dopamine metabolite concentrations in the CSF of healthy adults (Hartikainen et al., 1991), schizophrenia patients and Alzheimer's patients (Losonczy et al., 1984), as well as in the postmortem hypothalamic tissue of individuals without neurological or psychiatric disease and ventral striatal tissue of schizophrenia patients (Karson et al., 1984). However, there have been no investigations of seasonal effects on regional dopamine function in the healthy living human brain. Using ${ }^{18} \mathrm{~F}-\mathrm{DOPA}$ positron emission tomography (PET), a method that reliably assays presynaptic dopamine synthesis in the striatum, we studied 86 healthy individuals, each at a different time throughout the year, hypothesizing that striatal dopamine synthesis would be greater during fall and winter than spring and summer.

\section{Materials and Methods}

Eighty-six healthy volunteers (ages, $22-49$ years; mean, $32.9 \pm 8.4$ years; 44 women, 8 non-Caucasian) without psychiatric, neurological, or major medical illness, as assessed by physician-administered standardized clinical interview (First et al., 1996), medical history, and physical examina- 
tion, participated after providing informed consent as approved by the National Institute of Mental Health Institutional Review Board and National Institutes of Health (NIH) Radiation Safety Committee. Each participant was recruited from the local community (Washington, DC metropolitan area) and completed one scanning session at the NIH Clinical Center in Bethesda, MD as part of a separate, ongoing protocol. Sessions were scheduled between 10:00 A.M. and 2:00 P.M. throughout the calendar year, and their date relative to the autumnal and vernal equinoxes delineated whether the associated season was fall-winter or spring-summer (Karson et al., 1984). There were 44 spring-summer (mean, $32.1 \pm 7.7$ years; 22 women; 6 non-Caucasian) and 42 fall-winter (mean, $33.8 \pm 9.1$ years; 22 women; 2 non-Caucasian) scans. There were no significant differences between seasonal groups in sex, age, ethnicity, or year of acquisition.

Each participant abstained from nicotine and caffeine for $4 \mathrm{~h}$ and from food for $6 \mathrm{~h}$ before their scanning session. One hour before ${ }^{18} \mathrm{~F}$-DOPA injection, they received a single oral dose of carbidopa (200 mg) to limit peripheral tracer metabolism and augment tracer availability to the brain. PET data were acquired with a General Electric Advance 3D PET camera ( 32 planes, $6.5 \mathrm{~mm}$ full-width half-maximum) while volunteers were in an awake, resting state. After an 8 min transmission scan for attenuation correction, $8-16 \mathrm{mCi}$ of ${ }^{18} \mathrm{~F}-\mathrm{DOPA}$ were injected and, $90 \mathrm{~s}$ after injection, a set of 25 scans was dynamically acquired over 90 $\mathrm{min}$. There were no changes in acquisition procedures or hardware throughout the study.

After attenuation correction, these ${ }^{18} \mathrm{~F}$-DOPA scans were registered to the last image and affine-normalized to an ${ }^{18} \mathrm{~F}$-DOPA PET template using Statistical Parametric Mapping software (SPM99; Wellcome Department of Cognitive Neurology, London, UK; http://www.fil.ion.ucl. ac.uk/spm/) (Friston et al., 1994). The kinetic rate constant $K_{\mathrm{i}}$ for ${ }^{18} \mathrm{~F}-$ DOPA uptake was calculated voxel-by-voxel using a linear fit based on the Patlak method (Patlak et al., 1983), with a time-activity curve in an occipital reference region as the input function (Whone et al., 2004). All time-activity curves were visually inspected to rule out saturation artifacts. Data were measured using $2 \mathrm{~mm}$ isotropic voxels and smoothed with a $10 \mathrm{~mm}$ Gaussian kernel to improve signal-to-noise ratios. Two regions of interest (ROIs; bilateral putamen and bilateral caudate) were defined using Wake Forest University PickAtlas software (PickAtlas2.4; Wake Forest University, Winston-Salem, North Carolina; http://fmri. wfubmc.edu/) (Maldjian et al., 2003).

To determine whether there existed a relationship between season and striatal presynaptic dopamine synthesis, a general linear model was adopted to perform two complimentary analyses of the calculated $K_{\mathrm{i}}$ maps. First, the average $K_{\mathrm{i}}$ values for each ROI were extracted and compared across seasons using SPSS software (SPSS 12.0, SPSS). Second, seasonal comparisons were made on a voxelwise basis for $K_{\mathrm{i}}$ values within the striatum from fall-winter and spring-summer scans using SPM with a voxel-level false-discovery rate $(p<0.05)$ correction for multiple comparisons (Genovese et al., 2002).

\section{Results}

One-sample Kolmogorov-Smirnov tests on striatal ROI values for the entire cohort and for spring-summer and fall-winter groups separately revealed no significant differences from the normal distribution. Bilateral putamen mean $K_{\mathrm{i}}$ was significantly greater during the fall-winter period $(0.0073 \pm 0.0007)$ than spring-summer $(0.0070 \pm 0.0007 ;$ mean difference $=0.0003 ; t=$ 2.10; $\mathrm{df}=84 ; p=0.038)$. When analyzed separately, both right and left putamen mean $K_{\mathrm{i}}$ showed the same effect (right putamen, mean difference $=0.0003, t=2.08, \mathrm{df}=84, p=0.040$; left putamen, mean difference $=0.0003, t=2.02, \mathrm{df}=84, p=$ 0.046). Uptake in the caudate (total mean $=0.0055 \pm 0.0005$ ) showed no significant seasonal effects. These results remained significant after controlling for sex, age, and ethnicity. Age and ethnicity were not predictive of mean $K_{\mathrm{i}}$ in the putamen or caudate. Both putamen and caudate mean $K_{\mathrm{i}}$ were greater in women than men (putamen ROI, mean difference $=0.0005, t=3.34$, $\mathrm{df}=84, p=0.001$; caudate ROI, mean difference $=0.0004, t=$ 3.30, $\mathrm{df}=84, p=0.001$ ), consistent with previous reports (Laakso et al., 2002). There were no sex-by-season interactions. Voxelwise analysis of the striatum confirmed the seasonal findings, yielding a large cluster in the left caudal putamen where fall-winter scans had greater $K_{\mathrm{i}}$ than spring-summer scans [peak voxel coordinates (Montreal Neurological Institute): $-30,-6,6$; $k=117 ; p<0.05$, false-discovery rate corrected for multiple comparisons] (Fig. 1). Post hoc voxelwise analyses also revealed voxels in the right putamen showing the same seasonal effect (fall-winter $>$ spring-summer) beginning at $p<0.002$, uncorrected. There were no regions where spring-summer scans had greater uptake than fall-winter scans. There were no significant associations between the time of day that the scan was acquired and either ROI or voxelwise measures of striatal $K_{\mathrm{i}}$.

\section{Discussion}

Though previous studies in rodents (Naber et al., 1981; CastilloRomero et al., 1993; Masubuchi et al., 2000; Uz et al., 2003) and indirect evidence from humans (Karson et al., 1984; Losonczy et 
al., 1984; Hartikainen et al., 1991) have suggested dopaminebiorhythm interactions, this is, to our knowledge, the first study demonstrating an effect of season on in vivo measurements of striatal dopamine in healthy, young adults. Individuals who underwent ${ }^{18} \mathrm{~F}$-DOPA PET scans during the fall and winter seasons showed higher striatal $K_{\mathrm{i}}$ values, suggestive of greater presynaptic dopamine synthesis and storage, in the putamen. These results could not be explained by differences in sex or age and are in agreement with the direction of several past experimental findings using CSF homovanillic acid (Losonczy et al., 1984; Hartikainen et al., 1991) and postmortem brain tissue dopamine and homovanillic acid (Karson et al., 1984).

As yearly fluctuations in circadian rhythms underlie circannual changes (Lewy et al., 2006), it is notable that we found seasonal effects in the caudal putamen, a region of the striatum that receives its dopaminergic innervation predominantly from the substantia nigra and shows the greatest involvement in hereditary progressive dystonia with marked diurnal fluctuation (Segawa Disease). This is an illness in which GCH1 mutations result in reduced dopaminergic synthetic activity at nigrostriatal nerve terminals and pronounced circadian fluctuations in motor symptomatology (Segawa, 2000). By what mechanism this region might be particularly sensitive to chronobiological factors is not known and cannot be directly assessed by the present data, but one possibility might lie in striatal melatonin-dopamine interactions (Zisapel, 2001).

We found greater striatal presynaptic dopamine synthesis during the fall and winter season, when circadian cycles feature longer scotoperiods and thereby greater cumulative melatonin release (Kivelä et al., 1988; Stokkan and Reiter, 1994; Wehr, 1997; Morera and Abreu, 2006; but see Sack et al., 1986). Melatonin shows a complicated interaction with subcortical dopaminergic systems, both directly inhibiting postsynaptic striatal dopaminergic signaling and promoting presynaptic dopamine neuronal integrity via both antioxidant and tissue-specific mechanisms (Zisapel, 2001; Venero et al., 2002). Thus, the current data invite speculation that they may be a downstream melatonin effect, compensating for the postsynaptic inhibition (Zisapel, 2001) and/or resulting from upregulation of dopamine synthesis in midbrain dopaminergic neurons projecting to the striatum (Venero et al., 2002). Interestingly, because sleep quality shows seasonal variation and association with melatonin levels (Zeitzer et al., 2007; McLaughlin et al., 2008), this may be consistent with recent evidence linking striatal $\mathrm{D}_{2 / 3}$ receptor binding, measured by ${ }^{11} \mathrm{C}$-raclopride PET, with sleep deprivation in healthy humans, suggesting dopaminergic involvement in regulation of wakefulness in response to sleep-wake cycle fluctuations (Volkow et al., 2008, 2009). Future studies designed to uncover the character of melatonin-dopamine interactions in living humans are essential to evaluate these hypotheses.

A longitudinal design, with each participant undergoing multiple ${ }^{18} \mathrm{~F}$-DOPA scans throughout the year, would be a preferable and more sensitive approach (albeit limited in feasibility due to prescribed radiation limits). With future technical advances in PET, longitudinally designed studies will be helpful to confirm and extend these initial findings. Nonetheless, the fact that the studied seasonal groups were well balanced for number, age (Sack et al., 1986), and gender and were of substantial sample size, strengthens the present results. Additionally, the fact that data were continuously acquired over several years, rather than a single annual cycle, with the same hardware and acquisition procedures minimizes the possibility of secular drift in the data. Finally, it is important to highlight that the seasonal effects reported here may be a result either of climatic variables (e.g., photoperiodicity, temperature variation) or of unmeasured environmental (e.g., diet) or behavioral (e.g., physical activity) factors, and future experiments aimed at delineating these influences are necessary to better characterize the present results.

In conclusion, there exists an association between season and presynaptic striatal dopamine synthesis in healthy humans. Future work is merited to elucidate the nature of this relationship in the context of other neurotransmitter systems showing circannual variation (e.g., melatonin) and its potential implications for both the pathophysiology of and novel treatment approaches to neuropsychiatric illnesses with cyclical phenomenology.

\section{References}

Cannon DM, Klaver JM, Peck SA, Rallis-Voak D, Erickson K, Drevets WC (2009) Dopamine type-1 receptor binding in major depressive disorder assessed using positron emission tomography and [11C]NNC-112. Neuropsychopharmacology 34:1277-1287.

Castillo-Romero JL, Vives-Montero F, Reiter RJ, Acuña-Castroviejo D (1993) Pineal modulation of the rat caudate-putamen spontaneous neuronal activity: roles of melatonin and vasotocin. J Pineal Res 15:147-152.

First MB, Gibbon M, Spitzer RL, Williams JBW (1996) User's guide for the SCID-I for DSM-IV axis I disorders: research version. New York: Biometrics Research.

Friston KJ, Holmes AP, Worsley KJ, Poline JP, Frith CD, Frackowiak RS (1994) Statistical parametric maps in functional imaging: a general linear approach. Hum Brain Mapp 2:189-210.

Genovese CR, Lazar NA, Nichols T (2002) Thresholding of statistical maps in functional neuroimaging using the false discovery rate. Neuroimage 15:870-878.

Hartikainen P, Soininen H, Reinikainen KJ, Sirviö J, Soikkeli R, Riekkinen PJ (1991) Neurotransmitter markers in the cerebrospinal fluid of normal subjects: effects of aging and other confounding factors. J Neural Transm Gen Sect 84:103-117.

Huerta-Fontela M, Galceran MT, Ventura F (2008) Stimulatory drugs of abuse in surface waters and their removal in a conventional drinking water treatment plant. Environ Sci Technol 42:6809-6816.

Karson CN, Berman KF, Kleinman J, Karoum F (1984) Seasonal variation in human central dopamine activity. Psychiatry Res 11:111-117.

Kivelä A, Kauppila A, Ylöstalo P, Vakkuri O, Leppäluoto J (1988) Seasonal, menstrual and circadian secretions of melatonin, gonadotropins and prolactin in women. Acta Physiol Scand 132:321-327.

Laakso A, Vilkman H, Bergman J, Haaparanta M, Solin O, Syvälahti E, Salokangas RK, Hietala J (2002) Sex differences in striatal presynaptic dopamine synthesis capacity in healthy subjects. Biol Psychiatry 52:759-763.

Lewy AJ, Kern HA, Rosenthal NE, Wehr TA (1982) Bright artificial light treatment of a manic-depressive patient with a seasonal mood cycle. Am J Psychiatry 139:1496-1498.

Lewy AJ, Lefler BJ, Emens JS, Bauer VK (2006) The circadian basis of winter depression. Proc Natl Acad Sci U S A 103:7414-7419.

Losonczy MF, Mohs RC, Davis KL (1984) Seasonal variations of human lumbar CSF neurotransmitter metabolite concentrations. Psychiatry Res $12: 79-87$.

Maldjian JA, Laurienti PJ, Kraft RA, Burdette JH (2003) An automated method for neuroanatomic and cytoarchitectonic atlas-based interrogation of fMRI data sets. Neuroimage 19:1233-1239.

Mari F, Politi L, Biggeri A, Accetta G, Trignano C, Di Padua M, Bertol E (2009) Cocaine and heroin in waste water plants: a 1-year study in the city of Florence, Italy. Forensic Sci Int 189:88-92.

Masubuchi S, Honma S, Abe H, Ishizaki K, Namihira M, Ikeda M, Honma K (2000) Clock genes outside the suprachiasmatic nucleus involved in manifestation of locomotor activity rhythm in rats. Eur J Neurosci 12:4206-4214.

McLaughlin C, Bowman ML, Bradley CL, Mistlberger RE (2008) A prospective study of seasonal variation in shift work tolerance. Chronobiol Int 25:455-470.

Morera AL, Abreu P (2006) Seasonality of psychopathology and circannual melatonin rhythm. J Pineal Res 41:279-283.

Naber D, Wirz-Justice A, Kafka MS, Tobler I, Borbély AA (1981) Seasonal variations in the endogenous rhythm of dopamine receptor binding in rat striatum. Biol Psychiatry 16:831-835. 
Neumeister A, Willeit M, Praschak-Rieder N, Asenbaum S, Stastny J, Hilger E, Pirker W, Konstantinidis A, Kasper S (2001) Dopamine transporter availability in symptomatic depressed patients with seasonal affective disorder and healthy controls. Psychol Med 31:1467-1473.

Patlak CS, Blasberg RG, Fenstermacher JD (1983) Graphical evaluation of blood-to-brain transfer constants from multiple-time uptake data. J Cereb Blood Flow Metab 3:1-7.

Reith J, Benkelfat C, Sherwin A, Yasuhara Y, Kuwabara H, Andermann F, Bachneff S, Cumming P, Diksic M, Dyve SE, Etienne P, Evans AC, Lal S, Shevell M, Savard G, Wong DF, Chouinard G, Gjedde A (1994) Elevated dopa decarboxylase activity in living brain of patients with psychosis. Proc Natl Acad Sci U S A 91:11651-11654.

Rosenthal NE, Lewy AJ, Wehr TA, Kern HE, Goodwin FK (1983) Seasonal cycling in a bipolar patient. Psychiatry Res 8:25-31.

Rosenthal NE, Sack DA, Gillin JC, Lewy AJ, Goodwin FK, Davenport Y, Mueller PS, Newsome DA, Wehr TA (1984) Seasonal affective disorder: a description of the syndrome and preliminary findings with light therapy. Arch Gen Psychiatry 41:72-80.

Roybal K, Theobold D, Graham A, DiNieri JA, Russo SJ, Krishnan V, Chakravarty S, Peevey J, Oehrlein N, Birnbaum S, Vitaterna MH, Orsulak P, Takahashi JS, Nestler EJ, Carlezon WA Jr, McClung CA (2007) Mania-like behavior induced by disruption of CLOCK. Proc Natl Acad Sci U S A 104:6406-6411.

Sack RL, Lewy AJ, Erb DL, Vollmer WM, Singer CM (1986) Human melatonin production decreases with age. J Pineal Res 3:379-388.

Segawa M (2000) Hereditary progressive dystonia with marked diurnal fluctuation. Brain Dev 22 [Suppl]:S65-S80.

Sher L, Oquendo MA, Galfalvy HC, Zalsman G, Cooper TB, Mann JJ (2005) Higher cortisol levels in spring and fall in patients with major depression. Prog Neuropsychopharmacol Biol Psychiatry 29:529-534.

Stokkan KA, Reiter RJ (1994) Melatonin rhythms in Arctic urban residents. J Pineal Res 16:33-36.

Uz T, Akhisaroglu M, Ahmed R, Manev H (2003) The pineal gland is critical for circadian Period 1 expression in the striatum and for circadian cocaine sensitization in mice. Neuropsychopharmacology 28:2117-2123.
Uz T, Arslan AD, Kurtuncu M, Imbesi M, Akhisaroglu M, Dwivedi Y, Pandey GN, Manev H (2005) The regional and cellular expression profile of the melatonin receptor MT1 in the central dopaminergic system. Brain Res Mol Brain Res 136:45-53.

Venero JL, Absi el-H, Cano J, Machado A (2002) Melatonin induces tyrosine hydroxylase mRNA expression in the ventral mesencephalon but not in the hypothalamus. J Pineal Res 32:6-14.

Volkow ND, Wang GJ, Telang F, Fowler JS, Logan J, Wong C, Ma J, Pradhan K, Tomasi D, Thanos PK, Ferré S, Jayne M (2008) Sleep deprivation decreases binding of [11C] raclopride to dopamine D2/D3 receptors in the human brain. J Neurosci 28:8454-8461.

Volkow ND, Tomasi D, Wang GJ, Telang F, Fowler JS, Wang RL, Logan J, Wong C, Jayne M, Swanson JM (2009) Hyperstimulation of striatal D2 receptors with sleep deprivation: implications for cognitive impairment. Neuroimage 45:1232-1240.

Wehr TA (1997) Melatonin and seasonal rhythms. J Biol Rhythms 12:518-527.

Whone AL, Bailey DL, Remy P, Pavese N, Brooks DJ (2004) A technique for standardized central analysis of 6-[18]F-fluoro-L-DOPA PET data from a multicenter study. J Nucl Med 45:1135-1145.

Wong DF, Pearlson GD, Tune LE, Young LT, Meltzer CC, Dannals RF, Ravert HT, Reith J, Kuhar MJ, Gjedde A (1997) Quantification of neuroreceptors in the living human brain. IV. Effect of aging and elevations of D2like receptors in schizophrenia and bipolar illness. J Cereb Blood Flow Metab 17:331-342.

Zarate CA Jr, Payne JL, Singh J, Quiroz JA, Luckenbaugh DA, Denicoff KD, Charney DS, Manji HK (2004) Pramipexole for bipolar II depression: a placebo-controlled proof of concept study. Biol Psychiatry 56:54-60.

Zeitzer JM, Duffy JF, Lockley SW, Dijk DJ, Czeisler CA (2007) Plasma melatonin rhythms in young and older humans during sleep, sleep deprivation, and wake. Sleep 30:1437-1443.

Zisapel N (2001) Melatonin-dopamine interactions: from basic neurochemistry to a clinical setting. Cell Mol Neurobiol 21:605-616. 